\title{
AVALIAÇÃO E DISTRIBUIÇÃO DE MUDAS DE ESPÉCIES ARBÓREAS INOCULADAS COM FUNGOS MICORRÍZICOS PARA ATUAR NA REABILITAÇÃO DE ÁREAS IMPACTADAS PELA EXTRAÇÃO DE ARGILA EM MARABÁ-PA
}

\author{
Eliade Rocha dos Santos ${ }^{1}$; Andréa Hentz de Mello² ${ }^{2}$ Jayane Santos Nunes ${ }^{1}$; Clarissa Mendes \\ Knoechelmann $^{3}$; Raimundo Nonato do Espírito Santos ${ }^{4}$; Ana Valéria dos Reis Pinheiro ${ }^{4}$ \\ ${ }^{1}$ Discente do curso de Agronomia, Faculdade de Ciências Agrárias de Marabá (FCAM), Universidade Federal do Pará \\ (UFPA), Bolsista do SINDCERV, eliade_rs@ hotmail.com \\ ${ }^{2}$ Professora Adjunta II, FCAM, UFPA, andreahentz@ufpa.br \\ ${ }^{3}$ Professora Assistente I, FCAM, UFPA,clarissa@ufpa.br \\ ${ }^{4}$ Professor Adjunto, Faculdade de Geologia, UFPA
}

\begin{abstract}
RESUMO: A exploração de argila na cidade de Marabá tem causado uma série de impactos negativos ao meio físico. A atividade de extração de argila implica na retirada da vegetação natural e intensa movimentação de solo, gerando em alguns casos consideráveis buracos que contribuem para o distúrbio da área, além de promover com a retirada dos nutrientes, alta toxidez de metais no solo. Diante da necessidade da recuperação dos ecossistemas impactados, este tem como objetivo a produção de mudas arbóreas nativas inoculadas com fungos micorrízicos arbusculares (FMAs), para repor a vegetação antes existente, servir de cerca viva para conter a erosão hídrica e eólica do solo e propiciar um ambiente favorável ao desenvolvimento da microbiota do solo, avaliando a taxa de germinação de cada espécie. O inóculo de FMAs está sendo produzido através do cultivo armadilha com Brachiaria brizantha em casa de vegetação. As mudas de sabiá e acácia foram produzidas com substrato da área de rejeito e aos 90 dias foram inoculados com os FMAs e aos 120 dias levadas à campo. A taxa de germinação em casa de vegetação total variou de acordo com a espécie, sendo que o sabiá teve uma taxa de germinação de 9,3\% e de Acácia 32,5\%. Aos 60 dias após a germinação as mudas de acácia tiveram um melhor desenvolvimento em altura, número de folhas, número de pecíolos, número de cotilédones e número de folíolos, quando comparadas as mudas de sabiá e no campo estão tendo desenvolvimento uniforme e satisfatório.
\end{abstract}

PALAVRAS-CHAVE: Exploração de argila, recuperação paisagística, micorrizas.

\section{EVALUACIÓN Y DISTRIBUCIÓN DE PLÁNTULAS DE ESPECIES DE ARBOLES INOCULADAS CON HONGOS MICORRÍZÓGENOS PARA REALIZAR LA REHABILITACIÓN DE ZONAS AFECTADAS POR LA EXTRACCIÓN DE ARCILLA EN MARABÁ-PA}

RESUMEN: La exploración de la arcilla en la ciudad de Marabá ha provocado una serie de impactos negativos sobre el medio ambiente físico. La actividad de extracción de arcilla implica la eliminación de la vegetación natural y el intenso movimiento de suelo, la creación de agujeros considerables en algunos casos contribuyen a la alteración de la zona, y promover la retirada de nutrientes, toxicidad de los metales de alta en el suelo. Dada la necesidad de la restauración de los ecosistemas afectados, su objetivo es la producción de plántulas de árboles nativos inoculadas con hongos micorrizógenos arbusculares (HMA), en sustitución de la vegetación existente antes, servir como cerca viva para contener la erosión hídrica y eólica del suelo y proporcionar un entorno

Agroecossistemas, v. 2, n. 1, p. 8-11, 2010 
propicio para el desarrollo de las comunidades microbianas del suelo, determinar el porcentaje de germinación de cada especie. El inóculo de HMA se produce a través de la cultura de la trampa con Brachiaria brizantha en un invernadero. Las plántulas de acacia y el tordo se produjeron con una superficie del sustrato de relaves y 90 días fueron inoculadas con la AMF a los 120 días y trasladado al campo. La tasa de germinación en invernadero total varió según la especie y que el tordo tenía una tasa de germinación de 9,3\% y el 32,5\% de Acacia. A los 60 días después de la germinación de las plántulas de acacia había un mejor desarrollo en altura, número de hojas, número de pecíolo, el número de cotiledones y el número de hojas, en comparación con las plántulas en el campo de sabiá y estan teniendo un desarrollo uniforme y satisfactorio.

PALABRAS CLAVE: Exploración de la arcilla, restauración del paisaje, micorrizas.

\section{INTRODUÇÃO}

Uma área pode ser considerada degradada quando a vegetação, a fauna e a camada fértil do solo são destruídas, ou seja, quando houver alterações físicas,químicas e biológicas de forma a prejudicar o meio ambiente e o potencial sócio econômico da área, esta pode ser considerada como degradada.

A remoção dos horizontes superficiais do solo é considerada um dos pontos mais críticos da degradação de áreas, devido aos problemas causados na estrutura e na atividade biológica do solo. A atividade de extração de argila implica na retirada da vegetação natural e intensa movimentação de solo, gerando em alguns casos consideráveis buracos que contribuem para o distúrbio da área, além de promover com a retirada dos nutrientes, alta toxidez de metais no solo (EMBRAPA, 2000).

O processo de recuperação de áreas degradadas requer conhecimento do histórico da área a ser recuperada, referente ao tipo de degradação ocorrida, características físicas e químicas do solo, composição florística original e comunidade microbiológica do solo. A microbiota do solo atua na decomposição da matéria orgânica e liberação de nutrientes, na formação e estabilização de agregados e na ciclagem de nutrientes. Dentre os microrganismos, os simbiontes destacamse por interagir diretamente com as espécies vegetais, participando dos processos de absorção de nutrientes, relações hídricas, crescimento e reprodução (MOREIRA, 2000).

Diante da necessidade da recuperação dos ecossistemas impactados, este trabalho, teve como objetivo geral a produção de mudas de sabiá e acácia inoculadas com fungos micorrízicos arbusculares (FMA's), para repor a vegetação antes existente e servir de cerca viva para conter a erosão hídrica e eólica do solo.

\section{MATERIAL E MÉTODOS}

O inóculo de FMA's para inoculação foi produzido através do cultivo armadilha com Brachiaria brizantha em areia de praia com fornecimento de água três vezes ao dia

Agroecossistemas, v. 2, n. 1, p. 8-11, 2010 
no período de germinação até atingir $15 \mathrm{~cm}$ de altura em casa de vegetação. Os fungos micorrízicos que foram isolados e estão sendo multiplicados, foram decorrentes da área de rejeito, onde foram extraídos do solo, através da técnica de extração e centrifugação em sacarose.

A extração de esporos de FMA's no solo consistiu basicamente em extraí-los de $50 \mathrm{~g}$ de solo pela técnica de peneiramento úmido de (GERDEMANN; NICOLSON, 1963) e centrifugação em água e sacarose a 40\% (JENKINS, 1964).

A amostra de solo foi suspendida em 1 litro de água, em um béquer e agitada vigorosamente, seguida de decantação, por alguns segundos, para que ocorra sedimentação das partículas menores e/ou mais densas que os esporos. O sobrenadante é passado através de um conjunto de peneiras de malha $710 \mu \mathrm{m}$ a $45 \mu \mathrm{m}$, sobrepostas em um béquer, na seqüência da menor malha para a maior. Nas peneiras ficam retidos os esporos e algum solo e material orgânico (GERDEMANN; NICOLSON, 1963).

O material retido nas peneiras foi transferido para tubos de centrífuga com capacidade para $50 \mathrm{~mL}$, adicionando-se água. Os tubos foram pesados e centrifugados por três minutos a 2500 rpm. Depois da centrifugação, o sobrenadante foi cuidadosamente descartado, adicionando-se solução de sacarose á 40\%. O material (solo+esporos) sedimentado foi ressuspendido com auxílio de uma espátula e centrifugado novamente a $2500 \mathrm{rpm}$ por um minuto. $\mathrm{O}$ sobrenadante contendo esporos foi vertido em peneiras, lavado abundantemente com água corrente e recolhido em uma placa para avaliação e contagem (JENKINS, 1964).

As espécies arbóreas foram escolhidas devido já existirem na área antes da retirada da argila, e sendo leguminosas foram priorizadas por possuírem características de crescimento em condições edafoclimáticas nem sempre favoráveis, e capacidade de enriquecer o solo. Assim, foram semeadas as espécies de acácia (Acacia mangium), sabiá (Mimosa caesalpinifolia), no mês de setembro de 2009, e quando estavam com dois meses após a germinação entre os dias 27/10/2009 e 14/11/2009 foram avaliadas quanto aos parâmetros de crescimento como altura, número de folhas, número de pecíolos, número de cotilédones e número de folíolos e no dia 23 de dezembro foram levadas a campo na área do Sr. Edmilson Lacerda.

A taxa de germinação foi obtida através da regra de três simples, e os dados quanto aos demais parâmetros foram processados e avaliados quanto à variância através do teste de médias, Tukey a 5\% (FERREIRA, 2000)

Agroecossistemas, v. 2, n. 1, p. 8-12, 2010 


\section{RESULTADOS E DISCUSSÃO}

A taxa de germinação em casa de vegetação variou de acordo com a espécie, sendo que o sabiá teve uma taxa de germinação de $9,3 \%$ e a acácia de $32,5 \%$.
A Tabela 1 revela a taxa de crescimento das mudas de sabiá e acácia aos 60 dias após a germinação observada em casa de vegetação.

Tabela 1: Altura, número de folhas, número de pecíolos, número de cotilédones e número de folíolos de sabiá e acácia aos 60 dias após a germinação ( $\mathrm{N}=150)$.

\begin{tabular}{cccccc}
\hline ESPÉCIE & $\begin{array}{c}\text { ALTURA } \\
(\mathrm{cm})\end{array}$ & $\begin{array}{c}\mathrm{N}^{\circ} \mathrm{DE} \\
\text { FOLHAS }\end{array}$ & $\begin{array}{c}\mathrm{N}^{\circ} \mathrm{DE} \\
\text { PECÍOLOS }\end{array}$ & $\begin{array}{c}\mathrm{N}^{\circ} \mathrm{DE} \\
\text { COTILÉDONES }\end{array}$ & $\begin{array}{c}\mathrm{N}^{\circ} \mathrm{DE} \\
\text { FOLÍOLOS }\end{array}$ \\
\hline Sabiá & $3,86 \mathrm{~b}$ & $3,18 \mathrm{~b}$ & $3,27 \mathrm{~b}$ & $0,21 \mathrm{a}$ & $31,2 \mathrm{~b}$ \\
Acácia & $6,20 \mathrm{a}$ & $6,90 \mathrm{a}$ & $6,98 \mathrm{a}$ & $0,18 \mathrm{a}$ & $75,76 \mathrm{a}$ \\
\hline
\end{tabular}

Médias com letras iguais na mesma coluna não diferem estatisticamente pelo teste de tukey $5 \%$

Aos 60 dias após a germinação as mudas de acácia tiveram um melhor desenvolvimento em altura, número de folhas, número de pecíolos, número de cotilédones e número de folíolos, quando comparada as mudas de sabiá.

No campo, foram levadas com 120 dias após a germinação, e avaliadas 30 dias após o plantio, tendo $100 \%$ de sobrevivência no campo.

Estes dados foram importantes no processo de inoculação das mudas com os fungos micorrízicos e a sobrevivência das mudas no campo, uma vez que já estavam adaptadas ao substrato que é proveniente da área de rejeito, favorecendo assim, o maior desenvolvimento, e superação a perenização e as condições de estresse do ambiente.

\section{CONCLUSÕES}

A baixa germinação está relacionada com fatores como: oscilação de temperatura, variação na luminosidade, excesso de irrigação e baixo teor natural de germinação, indicando idade avançada da semente.

Aos 60 dias após a germinação as mudas de acácia tiveram um melhor desenvolvimento em altura, número de folhas, número de pecíolos, número de cotilédones e número de folíolos, quando comparadas as mudas de sabiá.

No campo, na área degradada pela extração de argila as mudas tiveram um excelente desenvolvimento aos 30 dias após o plantio. 


\section{REFERÊNCIAS}

FERREIRA, D. F. Sistemas de análise estatística para dados balanceados. Lavras:UFLA/DEX/SISVAR, 145p, 2000.

GERDEMAN, J.W.; NICOLSON, T.H. Spores of mycorrhizal Endogene species extracted from soil by wet sieving and decanting. Trans. Br. Mycol.Soc., v.46, p.235- 244, 1963.

JENKINS, W.R. A rapid centrifugal-flotation technique for separating nematodes from soil.

Pl. Dis. Rep., v. 48, p. 692, 1964.
MOREIRA, F. M. S.; SIQUEIRA, J. O. Microbiologia e bioquímica do solo. Lavras: Editora UFLA, 626p, 2002.

\section{AGRADECIMENTOS}

O presente trabalho foi realizado com o apoio do SINDCERV. 